\title{
Editorial
}

\section{Solid-State Lighting with High Brightness, High Efficiency, and Low Cost}

\author{
Ray-Hua Horng, ${ }^{1}$ Kei May Lau, ${ }^{2}$ Hao-Chung Kuo, ${ }^{3}$ and Nelson Tansu ${ }^{4}$ \\ ${ }^{1}$ Graduate Institute of Precision Engineering, National Chung Hsing University, Taichung 402, Taiwan \\ ${ }^{2}$ Photonics Technology Center, Department of Electronic and Computer Engineering, Hong Kong University of Science and Technology, \\ Clear Water Bay, Kowloon, Hong Kong \\ ${ }^{3}$ Department of Photonics and Institute of Electro-Optical Engineering, National Chiao Tung University, Hsinchu 30010, Taiwan \\ ${ }^{4}$ Center for Photonics and Nanoelectronics, Department of Electrical and Computer Engineering, Lehigh University, Bethlehem, \\ PA 18015, USA
}

Correspondence should be addressed to Ray-Hua Horng; huahorng@nchu.edu.tw and Nelson Tansu; tansu@lehigh.edu

Received 21 August 2014; Accepted 21 August 2014; Published 7 September 2014

Copyright (๑) 2014 Ray-Hua Horng et al. This is an open access article distributed under the Creative Commons Attribution License, which permits unrestricted use, distribution, and reproduction in any medium, provided the original work is properly cited.

In order to achieve the advanced lighting with the energysaving and environmental-protecting capabilities, the technologies of solid-state lighting have been developed rapidly. In all solid-state lighting applications, light-emitting diode (LED) is the most popular technique due to its advantages of small volume, long lifetime, high reliability, low power consumption, and nonpollution.

The progress in solid-state lighting has been driven by innovations in wide range of technologies in materials, devices, and novel concepts [1-5]. In addition to the progress in visible InGaN-based light-emitting diodes (LEDs) based on III-nitride based semiconductor, the improved understanding in the AlGaN-based LEDs [6, 7] has also resulted in new understanding on the device physics of III-nitride semiconductor physics which in turn results in new concept and approaches to handle the limitation in the fields of nitride-based LEDs. Several of these concepts have resulted in new approaches to suppress the charge separation effect $[8,9]$, carrier leakage process [10-14], light extraction issue [15-17], and Auger processes [18-21] in the InGaN-based LEDs. The improved understanding on the fundamental properties of In GaN as active regions has resulted in the ability to advance this field into practical technologies being implemented in the daily technologies used in our society.

In this special issue, the editors attempt to bring some of the recent advances in the field of device engineering and applications of III-nitride based LEDs with the goals of achieving high brightness and low-cost approaches. Up to now, the nitride-based materials are maturely developed to apply for LED applications. However, to obtain the LED devices with high brightness, high efficiency, and low cost, there are still some techniques to be improved, especially for the nitride-epilayer growth with low defect density and device fabrication with high heat dissipation.

In this special issue, there are seven contributed papers to discuss these issues from the LED epilayer quality to the high efficiency package. The implementation and test of LED-based lamp for lighthouse application were discussed at the system level ("Implementation and test of a LEDbased lamp for a lighthouse" by L. Mercatelli et al.). Such applications of LED in lighthouse have different requirement from those used in general illumination. The important new application from LED will broaden the new potential innovations required in enabling this technology to be suitable for implementation.

The investigation of novel phosphor material for converting blue/UV LEDs into white LEDs was also discussed specifically for investigating the color rendering index and its thermal stability ("Color rendering index thermal stability improvement of glass-based phosphor-converted white light-emitting diodes for solid-state lighting" by C.-C. Tsai). 
Phosphor-based materials are important, and the understanding of its stability at high temperature for ensuring stability in color rendering index in white LEDs is crucial for low-cost white LED.

The use of ZnO:YAG based metal-insulator-sem-iconductor (MIS) white LEDs was also reported with various insulator designs ("Low-cost $\mathrm{ZnO}$ :YAG-based metal-insulatorsemiconductor white light-emitting diodes with various insulators" by L.-C. Chen et al.). Specifically, the authors investigated the effect of various thicknesses of the silica and $\mathrm{MnZnO}$ based insulator on the MIS structure for LED applications.

Recent works have shown the importance of growing GaN-based LEDs on nanopatterned substrates [22-24], and the two related works were reported in this special issue ("Performance of InGaN light-emitting diodes fabricated on patterned sapphire substrates with modified top-tip cone shapes" by H.-H. Hsueh et al. and "Void shapes controlled by using interruption-free epitaxial lateral overgrowth of $\mathrm{GaN}$ films on patterned $\mathrm{SiO}_{2}$ AlN/sapphire template" by Y.-A. Chen et al.). The use of shape-engineered patterned sapphire substrate and patterned silica mask for achieving improved epitaxy in GaN LEDs was reported ("Performance of In $G a N$ light-emitting diodes fabricated on patterned sapphire substrates with modified top-tip cone shapes" by H.-H. Hsueh et al. and "Void shapes controlled by using interruption-free epitaxial lateral overgrowth of GaN films on patterned $\mathrm{SiO}_{2}$ AlN/sapphire template" by Y.-A. Chen et al.). The thermal management is an important issue for high power LEDs, and the use of diamond-like carbon heat-spreading layer was reported ("Thermal characteristics of In GaN/GaN flip-chip light emitting diodes with diamond-like carbon heat-spreading layers" by P.-Y. Tsai et al.).

The investigations of high-voltage LEDs in flip chip configurations have tremendous interests and potential impact for enabling reduced droop operation up to high power operation ("Efficiency and droop improvement in GaN-based high-voltage flip chip LEDs" by Y.-C. Chiang et al.). The use of high voltage design enables the low current density while the total output power can be accomplished. The droop issue has been one of the key limitations in LED development for lowcost applications, and the high voltage LED has the potential for addressing this droop issue from the circuit and systems level innovation in new solid-state lighting device systems.

We hope that the special issue will be of value for the research community in particular in driving this important topic on solid-state lighting. The great potential and promise of solid-state lighting are coming to reality, and the drive for innovation for achieving high brightness at low cost is important for enabling market penetration of this technology.

Ray-Hua Horng Kei May Lau Hao-Chung Kuo Nelson Tansu

\section{References}

[1] M. H. Crawford, "LEDs for solid-state lighting: performance challenges and recent advances," IEEE Journal on Selected Topics in Quantum Electronics, vol. 15, no. 4, pp. 1028-1040, 2009.

[2] N. Tansu, H. Zhao, G. Liu et al., "III-nitride photonics," IEEE Photonics Journal, vol. 2, no. 2, pp. 236-243, 2010.

[3] J. J. Wierer, J. Y. Tsao, and D. S. Sizov, "Comparison between blue lasers and light-emitting diodes for future solid-state lighting," Laser \& Photonics Reviews, vol. 7, pp. 963-993, 2013.

[4] N. Tansu, "Photonics-advances in fundamental sciences and engineering technologies of light," Photonics, vol. 1, no. 1, pp. 18, 2014.

[5] J. Han and A. V. Nurmikko, "Advances in AlGaInN blue and ultraviolet light emitters," IEEE Journal on Selected Topics in Quantum Electronics, vol. 8, no. 2, pp. 289-297, 2002.

[6] J. Zhang and N. Tansu, "Engineering of AlGaN-Delta-GaN quantum wells gain media for mid- and deep-ultraviolet lasers," IEEE Photonics Journal, vol. 5, no. 2, Article ID 2600209, 2013.

[7] Y. Taniyasu and M. Kasu, "Polarization property of deepultraviolet light emission from C-plane AlN/GaN short-period superlattices," Applied Physics Letters, vol. 99, no. 25, Article ID 251112, 2011.

[8] D. F. Feezell, J. S. Speck, S. P. Denbaars, and S. Nakamura, "Semipolar $\left(20^{-} 2^{-} 1\right)$ InGaN/GaN light-emitting diodes for high-efficiency solid-state lighting," Journal of Display Technology, vol. 9, no. 4, pp. 190-198, 2013.

[9] H. P. Zhao, G. Y. Liu, J. Zhang, J. D. Poplawsky, V. Dierolf, and N. Tansu, "Approaches for high internal quantum efficiency green InGaN light-emitting diodes with large overlap quantum wells," Optics Express, vol. 19, no. S4, pp. A991-A1007, 2011.

[10] G. Liu, J. Zhang, C. K. Tan, and N. Tansu, "Efficiency-droop suppression by using large-bandgap $\mathrm{AlGaInN}$ thin barrier layers in InGaN quantum-well light-emitting diodes," IEEE Photonics Journal, vol. 5, no. 2, Article ID 2201011, 2013.

[11] H. J. Kim, S. Choi, S.-S. Kim et al., "Improvement of quantum efficiency by employing active-layer-friendly lattice-matched InAlN electron blocking layer in green light-emitting diodes," Applied Physics Letters, vol. 96, no. 10, Article ID 101102, 2010.

[12] B. C. Lin, K. J. Chen, C. H. Wang et al., "Hole injection and electron overflow improvement in InGaN/GaN light-emitting diodes by a tapered AlGaN electron blocking layer," Optics Express, vol. 22, pp. 463-469, 2014.

[13] N. F. Gardner, G. O. Müller, Y. C. Shen et al., "Blue-emitting InGaN-GaN double-heterostructure light-emitting diodes reaching maximum quantum efficiency above $200 \mathrm{~A} / \mathrm{cm}^{2}$," Applied Physics Letters, vol. 91, no. 24, Article ID 243506, 2007.

[14] J. Xie, X. Ni, Q. Fan, R. Shimada, U. Ozgur, and H. Morko, "On the efficiency droop in InGaN multiple quantum well blue light emitting diodes and its reduction with $\mathrm{p}$-doped quantum well barriers," Applied Physics Letters, vol. 93, no. 12, Article ID 121107, 2008.

[15] K. McGroddy, A. David, E. Matioli et al., "Directional emission control and increased light extraction in GaN photonic crystal light emitting diodes," Applied Physics Letters, vol. 93, no. 10, Article ID 103502, 2008.

[16] J. J. Wierer Jr., A. David, and M. M. Megens, "III-nitride photonic-crystal light-emitting diodes with high extraction efficiency," Nature Photonics, vol. 3, no. 3, pp. 163-169, 2009.

[17] X. H. Li, R. Song, Y. K. Ee, P. Kumnorkaew, J. F. Gilchrist, and N. Tansu, "Light extraction efficiency and radiation patterns of 
III-nitride light-emitting diodes with colloidal microlens arrays with various aspect ratios," IEEE Photonics Journal, vol. 3, no. 3 , pp. 489-499, 2011.

[18] Y. C. Shen, G. O. Mueller, S. Watanabe, N. F. Gardner, A. Munkholm, and M. R. Krames, "Auger recombination in InGaN measured by photoluminescence," Applied Physics Letters, vol. 91, no. 14, Article ID 141101, 2007.

[19] K. T. Delaney, P. Rinke, and C. G. van de Walle, "Auger recombination rates in nitrides from first principles," Applied Physics Letters, vol. 94, no. 19, Article ID 191109, 2009.

[20] J. Iveland, L. Martinelli, J. Peretti, J. S. Speck, and C. Weisbuch, "Direct measurement of auger electrons emitted from a semiconductor light-emitting diode under electrical injection: identification of the dominant mechanism for efficiency droop," Physical Review Letters, vol. 110, no. 17, Article ID 177406, 2013.

[21] C.-K. Tan, J. Zhang, X.-H. Li, G. Liu, B. O. Tayo, and N. Tansu, "First-principle electronic properties of dilute-as GaNAs alloy for visible light emitters," Journal of Display Technology, vol. 9, no. 4, pp. 272-279, 2013.

[22] Y. K. Ee, J. M. Biser, W. Cao, H. M. Chan, R. P. Vinci, and N. Tansu, "Metalorganic vapor phase epitaxy of III-nitride lightemitting diodes on nanopatterned AGOG sapphire substrate by abbreviated growth mode," IEEE Journal on Selected Topics in Quantum Electronics, vol. 15, no. 4, pp. 1066-1072, 2009.

[23] Y. Li, S. You, M. Zhu et al., "Defect-reduced green GaInN/GaN light-emitting diode on nanopatterned sapphire," Applied Physics Letters, vol. 98, no. 15, Article ID 151102, 2011.

[24] Y.-J. Lee, C.-H. Chiu, C. C. Ke et al., "Study of the excitation power dependent internal quantum efficiency in InGaN/GaN LEDs grown on patterned sapphire substrate," IEEE Journal on Selected Topics in Quantum Electronics, vol. 15, no. 4, pp. 11371143, 2009. 

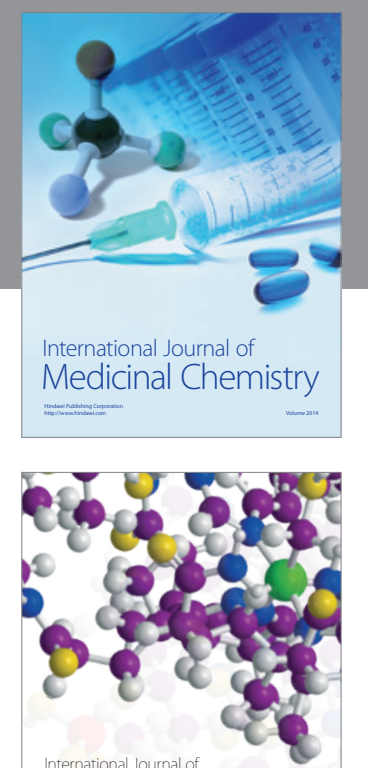

\section{Carbohydrate} Chemistry

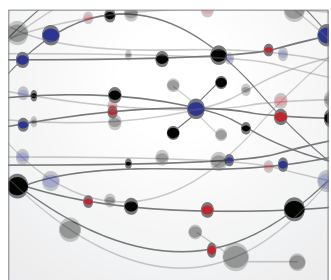

The Scientific World Journal
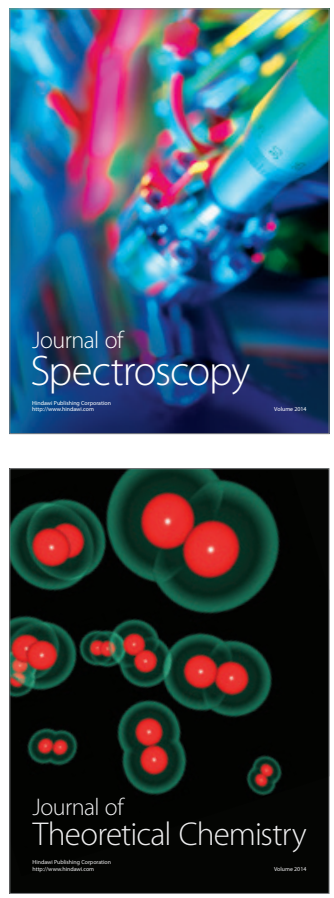
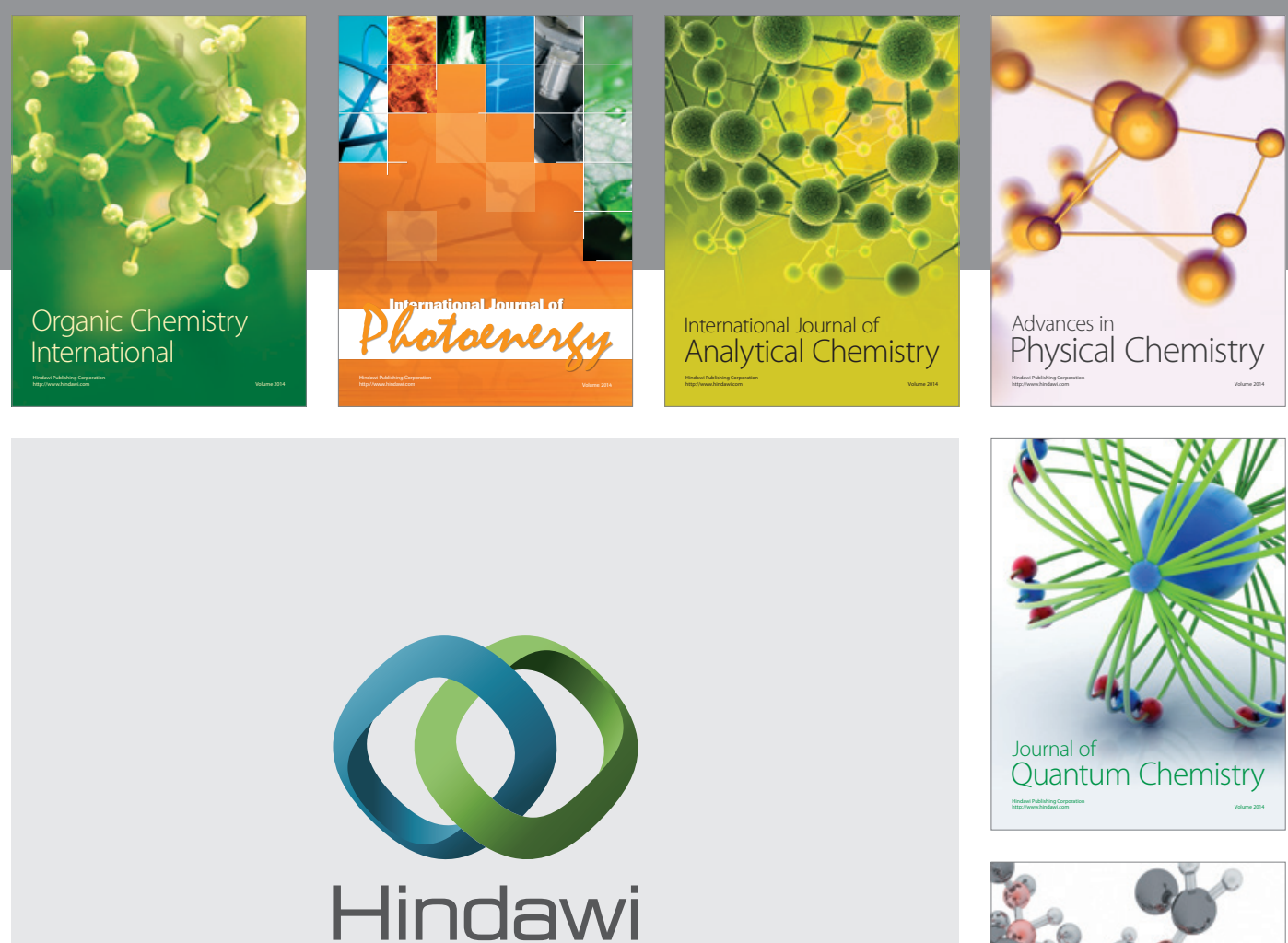

Submit your manuscripts at

http://www.hindawi.com

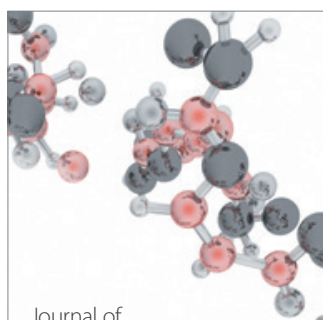

Analytical Methods

in Chemistry

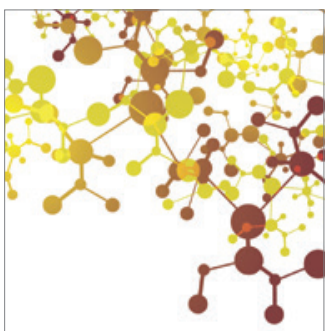

Journal of

Applied Chemistry

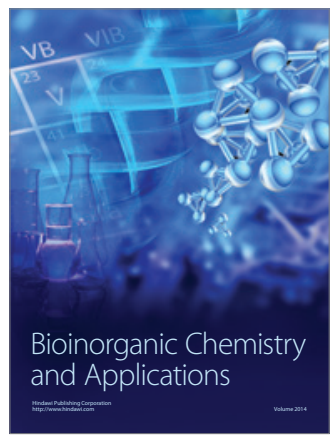

Inorganic Chemistry
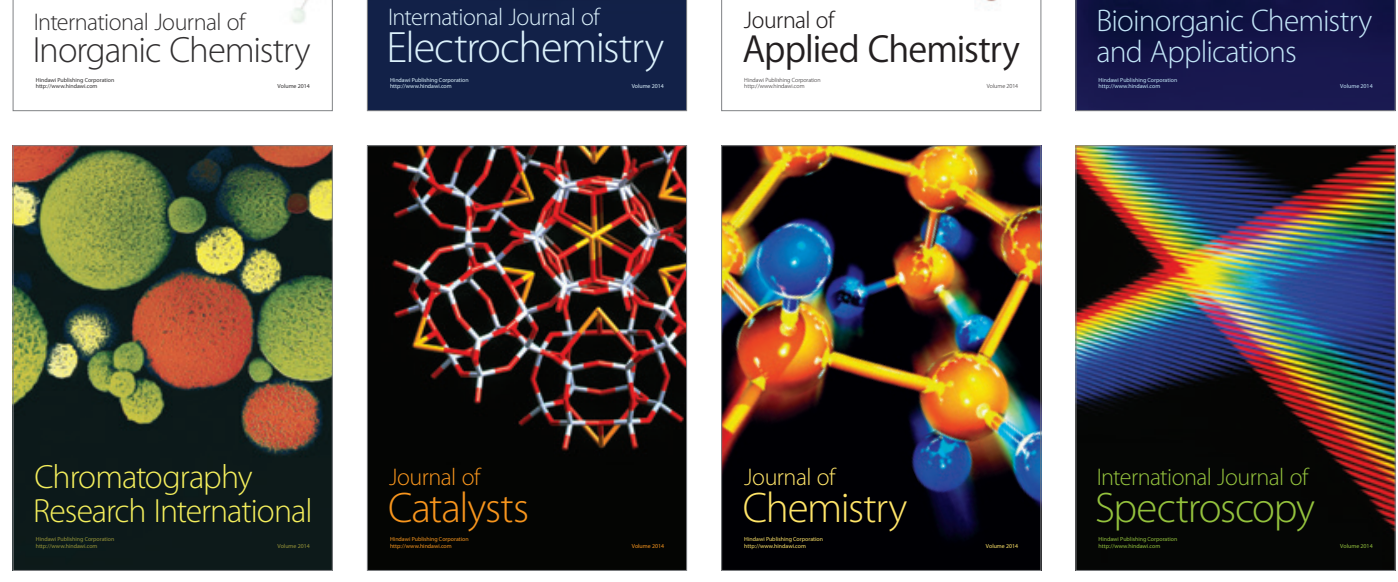